\title{
Determination of Taxonomic Status and Phylogenetic Affinities of Common Edible Crab Species in Southern Coast of Sri Lanka Using DNA Barcoding Gene Region
}

\author{
Benthotage Chamara Jayasankha De Silva*, Dona Hemali Nandana Munasinghe \\ Department of Zoology, Faculty of Science, University of Ruhuna, Sri Lanka
}

Copyright $\mathrm{C} 2016$ by authors, all rights reserved. Authors agree that this article remains permanently open access under the terms of the Creative Commons Attribution License 4.0 International License

\begin{abstract}
Edible crabs are among the known and valuable economic sea foods exported, as well as the consumed locally in southern Sri Lanka. However, genetic identification and taxonomic status of available crab species are less studied. This study identified ten selected varieties of edible crab species using information of barcoding gene region. Acquired consensus sequences of partially amplified mitochondrial COI gene region $(710 \mathrm{bp})$ were processed in BLAST option of NCBI database. Results identified six different species fallen within three genera, namely Scylla serrata, Scylla olivacea, Portunus pelagicus, Portunus sanguinolentus, Charybdis japonica and Charybdis natator which were confirmed with morphological keys. Identified sequences were analyzed with sequences from other geographical regions and Minimum Evolution Tree; sequence divergence levels among sequences were also estimated. Phylogenetic tree produced three separated clades with basal clade of Genus Portunus. Two P. pelagicus sequences have been linked with Australia and Russia independently, while two $P$. sanguinolentus sequences behaved as haplotypes, diverged slightly from South Korea, India and China. Scylla serrata sequences were promising a strong genetic uniformity with India and Thailand. However, in Scylla olivacea, two sequences related to India and Thailand separately. Sequence of Charybdis natator showed a greater similarity to Japanese sequence while samples collected as Charybdis japonica seems to be controversial and need further studies. As the first genetic study conducted to estimate taxonomic status of edible crabs in Sri Lanka, results are important for use in conservation strategies, as well as further research and prospective culturing programs.
\end{abstract}

Keywords Common Edible Crabs, COI Gene, DNA Barcoding, Southern Sri Lanka, Phylogeny

\section{Introduction}

It is much reasonable to deem that edible crabs (Crustacea: Decapoda: Portunidae) own an important food value because, they comprise a distinct taste as well as the unique nutritive value. Sri Lanka, being an island, has a coastal line of 1760 $\mathrm{km}$ in contact with estuaries and lagoons. These areas are considerably rich in crabs due to the habitat compatibility. Crab fishery may be of two main subsectors, marine crab fishery and lagoon or estuarine crab fishery. Nevertheless, fishers gain their income by both of sectors, especially by fulfilling the demand of overseas.

According to the past records, in Sri Lanka there are three popular species of edible crabs throughout the country. They are in the order of preference Scylla serrata (Forskal,1775), Portunus pelagicus (Linnaeus,1758) and Portunus sanguinolentus (Herbst, 1783) [9].

Scylla serrata is commonly known as "lagoon crab or mud crab" as they inhabit mostly the brackish water, usually just offshore on soft muddy bottoms among mangroves and is of great demand, in local and export markets. It is a large crab which can grow up to about $25 \mathrm{~cm}$ in carapace length and 1.5 $\mathrm{kg}$ in weight [9]. Portunus pelagicus is a marine species distributed throughout Indo-West Pacific region of which males are provided with blue markings, and females with dull green, hence referred to as 'blue swimming crab'. It is found from sandy to sandy-muddy substrates in shallow waters down to a depth of $50 \mathrm{~m}$, including areas near reefs, mangroves, and in sea grass and algal beds [1]. P. pelagicus also grows to a fairly large size of about $10-15 \mathrm{~cm}$ in carapace length, and attains a weight of about $500-750 \mathrm{~g}$ [9]. Portunus sanguinolentus is a swimming crab, coloured olive to dark green, with 3 prominent maroon to red spots on posterior $1 / 3$ of carapace which can grow up to maximum carapace width of $20 \mathrm{~cm}$. They inhabit sandy to sandy-muddy substrates, from the intertidal zone (especially juveniles) to depths of $30 \mathrm{~m}$. Although distribution is the 
same, this species is less common than Portunus pelagicus, and appears only occasionally in markets. It is priced similarly to, or for slightly lower prices as, $P$. pelagicus [1].

Genomic approaches to taxon diagnosis exploit diversity among DNA sequences to identify organisms [14]. Studies evaluated the potential of using COI as a taxonomic tool for species identification [7]. DNA barcoding has become a promising tool for rapid and accurate identification of various taxa and to reveal unrecognized species in several animal groups. Moreover, the introduction of DNA barcoding has highlighted the expanding use of the $\mathrm{COI}$ as a genetic marker for species identification [3].

Scylla serrate, commonly known as the giant mud crab, has been studied using DNA sequences by Fuseya and Watanabe [4]; Keenan et al. [11] and Gopurenko and Hughes [6]. Costa et al. [2] has highlighted the use of barcoding region of mitochondrial genome for the analysis of genetic data for crustaceans.

Past studies have pointed out that the identification of Scylla species using morphological data is controversial; especially, in larval and juvenile (crablet) stages [5]. Besides, $P$. pelagicus may be confused with $P$. trituberculatus, which resembles a large stocky female of $P$. pelagicus [1]. Therefore, utility of genetic information was recommended for identification of crab species [4]. This approach is more advantageous in crab fattening industry in which the larval stages are collected from the wild and reared them up to adult stage.
In addition to 3 popular species, i.e. Scylla serrata, Portunus pelagicus and $P$. sanguinolentus, there are many edible crab varieties available in Southern Sri Lanka, for which the exact taxonomic statuses are not determined. On the otherhand past studies based on morphological cues and molecular level identification of commercially important crab species has not been reported in Sri Lanka. Thus, there were two objectives of this study: to collect barcoding data of common edible crab species recorded in the southern coastal region of Sri Lanka and to determine their species status and phylogenetic affinities paired with relevant species recorded from other geographical regions of the world using data of the DNA barcoding gene region.

\section{Methods and Materials}

\subsection{Collection of Specimens and Preservation}

Edible crab samples were collected from several different fish landing sites and fish markets along the southern coastal belt of Sri Lanka, including Bentota, Balapitiya, Ambalangoda, Dodanduwa, Mahamodara, Galle, Habaraduwa, Weligama, Polwathumodara, Thotamuna (Matara), Pehembiya (Dikwella), Rekawa, Kahandamodara and Yala (Figure 1).

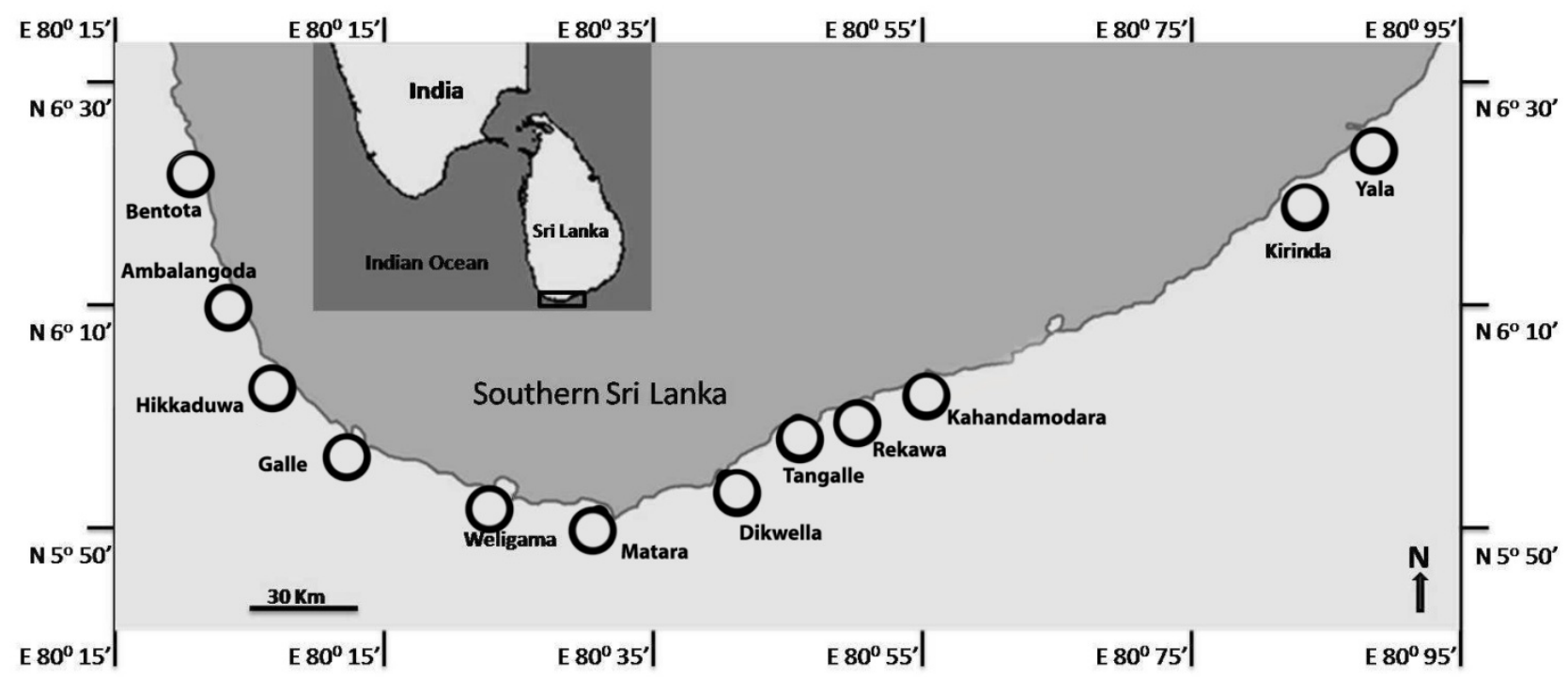

Figure 1. Sample collection sites of the current study, along the southern coastal belt of Sri Lanka 
During the collection process, at least three individuals from each variety at each site were collected including both sexes to the greatest extent possible. All collected species were identified using morphological characteristics according to the published keys for crustaceans [1].

After the morphometric categorization, minimum of two to three individuals from each morph; regardless of the site, were selected for the analysis. Seventeen selected specimens were dissected in order to acquire a muscle sample of 3-5 g with minimum damage to their body. Flesh samples were preserved in absolute ethanol. Remaining specimens were kept under cryogenic conditions at the Research Laboratory, Department of Zoology, University of Ruhuna, Matara, Sri Lanka as reference materials.

\subsection{DNA Extraction, PCR Amplification and Sequencing}

DNA extraction was carried out using QIAGEN DNeasy Blood \& Tissue Kit (USA). Partial amplification of around 710-bp fragment of mitochondrial COI (Cytochrome Oxidase Subunit I) gene region was performed using primers, LCO1490 and HCO2198. LCO1490: 5'-GGTCAACAAATCATAAAGATATTGG-3' and HCO2198: 5'-TAAACTTCAGGGT GACCAAAAAATCA3' (Folmer et al., 1994). Polymerase Chain Reaction was carried out in $25 \mu \mathrm{L}$ reaction volumes comprised of $5.0 \mu \mathrm{L}$ of template DNA extract, $2.5 \mu \mathrm{L}$ of $10 \mathrm{X}$ PCR buffer, $2.5 \mu \mathrm{L}$ of $15 \mathrm{mM} \mathrm{MgCl}_{2}, 2.5 \mu \mathrm{L}$ of $2 \mathrm{mM}$ of each dNTP, $2.0 \mu \mathrm{L}$ of 10 $\mu \mathrm{M}$ each forward and reverse primers, $2.0 \mu \mathrm{L}$ of Taq polymerase and $6.5 \mu \mathrm{L}$ of PCR water.

Thermal cycle for the reaction consisted of 2 minutes initial denaturing phase at $94{ }^{\circ} \mathrm{C}$, further 30 seconds at $94{ }^{\circ} \mathrm{C}$, 30 seconds primer annealing phase at $46{ }^{\circ} \mathrm{C}, 1$ minute elongation phase at $72{ }^{\circ} \mathrm{C}$ and final extension phase at $72{ }^{\circ} \mathrm{C}$ for 7 minutes. PCR amplicons which produced clear bands in agarose gel electrophoresis were sent to Macrogen Pvt. Ltd, South Korea for purification and sequencing.

\subsection{Analyses of Data}

\subsubsection{Determination of Species Status of Selected Specimens}

Acquired sequences were aligned, edited and finally consensus sequences were obtained with the aid of the BioEdit-Sequence Alignment Editor software package. Consensus sequences of each morph were compared with the maximum compatibility and similarity of pre-published sequences using the BLAST option (Basic Local Alignment Search Tool) of National Center for Biotechnology Information (NCBI) official database (http://blast.ncbi.nlm.nih.gov/Blast.cgi). Identified species were morphologically compared and confirmed using pre published reference materials [1].

\subsubsection{Publication of DNA Barcoding Data}

After clarification of the species status of samples collected, barcoding sequences were published in the data-base of National Center for Biotechnology Information (NCBI) and Barcode of Life Database (BOLD).

\subsubsection{Determination of Phylogenetic Status of Identified Species}

After justification of the species status, related sequences published in the Genbank from other geographical regions for each species were downloaded for analyses (Table 1).

Phylogenetic analyses were performed using MEGA 5.1 program. The Minimum Evolution tree was generated to estimate the strength of the phylogenetic relationship by taking 1000 as the bootstrap value. Hepatoporus orientalis (Sakai, 1935) (Crustacea, Decapoda, Brachyura, Xanthidae) was used as the out group taxa (GenBank: HM750994.1). Pairwise distance table ('P' distance) was constructed using the same options used for the estimation of the tree.

Table 1. Details of sequences downloaded from NCBI, published for relevant species in other geographical regions.

\begin{tabular}{|c|c|c|c|}
\hline NCBI accession number. & Species & Country, recorded & Abbreviations in the tree \\
\hline FJ827758.1 & Scylla serrata & Thailand & S.ser (5) THL \\
\hline KF612462.1 & Scylla serrata & India & S.ser (6) IND \\
\hline JN085429.1 & Scylla serrata & India & S.ser (7) IND \\
\hline KC200562.1 & Scylla serrata & India & S.ser (8) IND \\
\hline FJ827760.1 & Scylla olivacea & Thailand & S.oli (11) THL \\
\hline KC200563.1 & Scylla olivacea & India & S.oli (12) IND \\
\hline FJ812293.1 & Portunus pelagicus & Australia & P.pel (23) AUS \\
\hline JX398106.1 & Portunus pelagicus & Russia & P.pel (24) RUS \\
\hline EU284144.1 & Portunus sanguinolentus & China & P.san (29) CHN \\
\hline KC760157.1 & Portunus sanguinolentus & India & P.san (30) IND \\
\hline JX502943.1 & Portunus sanguinolentus & South Korea & P.san (31) SK \\
\hline EU586120.1 & Charybdis japonica & China & C.jap (19) CHN \\
\hline HM237597.1 & Charybdis japonica & China & C.jap (18) CHN \\
\hline HM237598.1 & Charybdis japonica & China & C.jap (17) CHN \\
\hline KF793328.1 & Charybdis natator & Japan & C.nat (22) JAP \\
\hline
\end{tabular}




\section{Results}

\subsection{Determination of Species Status of Several Crab Morphs}

BLAST results revealed that selected specimens belong to seven different species within three genera namely, Scylla serrata, Scylla olivacea (Herbst, 1796), Scylla tranquebarica (Fabricius, 1798), Portunus pelagicus, Portunus sanguinolentus, Charybdis japonica (A. Milne Edwards, 1861) and Charybdis natator (Herbst, 1789). However six species were confirmable without $S$. tranquebarica.

\subsection{Publication of DNA Barcoding Data}

Reference numbers for all sequences which were clearly identified and submitted to NCBI and BOLD Systems are given in Table 2 .

Table 2. Reference numbers of the NCBI and BOLD system for sequences derived from the current study.

\begin{tabular}{|c|c|c|}
\hline Sample identity/ Abbreviation & NCBI accession number & BOLD Systems accession number \\
\hline Charybdis natator 1 / 20.SSL & KM528124 & SLCRB001-14 \\
\hline Charybdis natator 2 / 21.SSL & KM528125 & SLCRB002-14 \\
\hline Portunus pelagicus $1 / 25 . S S L$ & KM528127 & SLCRB005-14 \\
\hline Portunus pelagicus 2 / 26.SSL & KM528126 & SLCRB006-14 \\
\hline Portunus sanguinolentus 1 / 27.SSL & KM528128 & SLCRB007-14 \\
\hline Portunus sanguinolentus 2 / 28.SSL & KM528129 & SLCRB008-14 \\
\hline Scylla olivacea 1 / 9.SSL & KM528131 & SLCRB003-14 \\
\hline Scylla olivacea 2 / 10.SSL & KM528130 & SLCRB004-14 \\
\hline Scylla serrata 1 / 1.SSL & KM528136 & SLCRB009-14 \\
\hline Scylla serrata 2 / 2.SSL & KM528132 & SLCRB011-14 \\
\hline Scylla serrata 3 / 3.SSL & KM528135 & SLCRB012-14 \\
\hline Scylla serrata 4 / 4.SSL & KM528134 & \\
\hline
\end{tabular}

\subsection{Determination of Phylogenetic Status of Identified Species}

Minimum evolution tree acquired in MEGA program is shown in Figure 2. Estimated sequence divergence levels among taxa obtained in this study are given in Table 3. 

in Southern Coast of Sri Lanka Using DNA Barcoding Gene Region

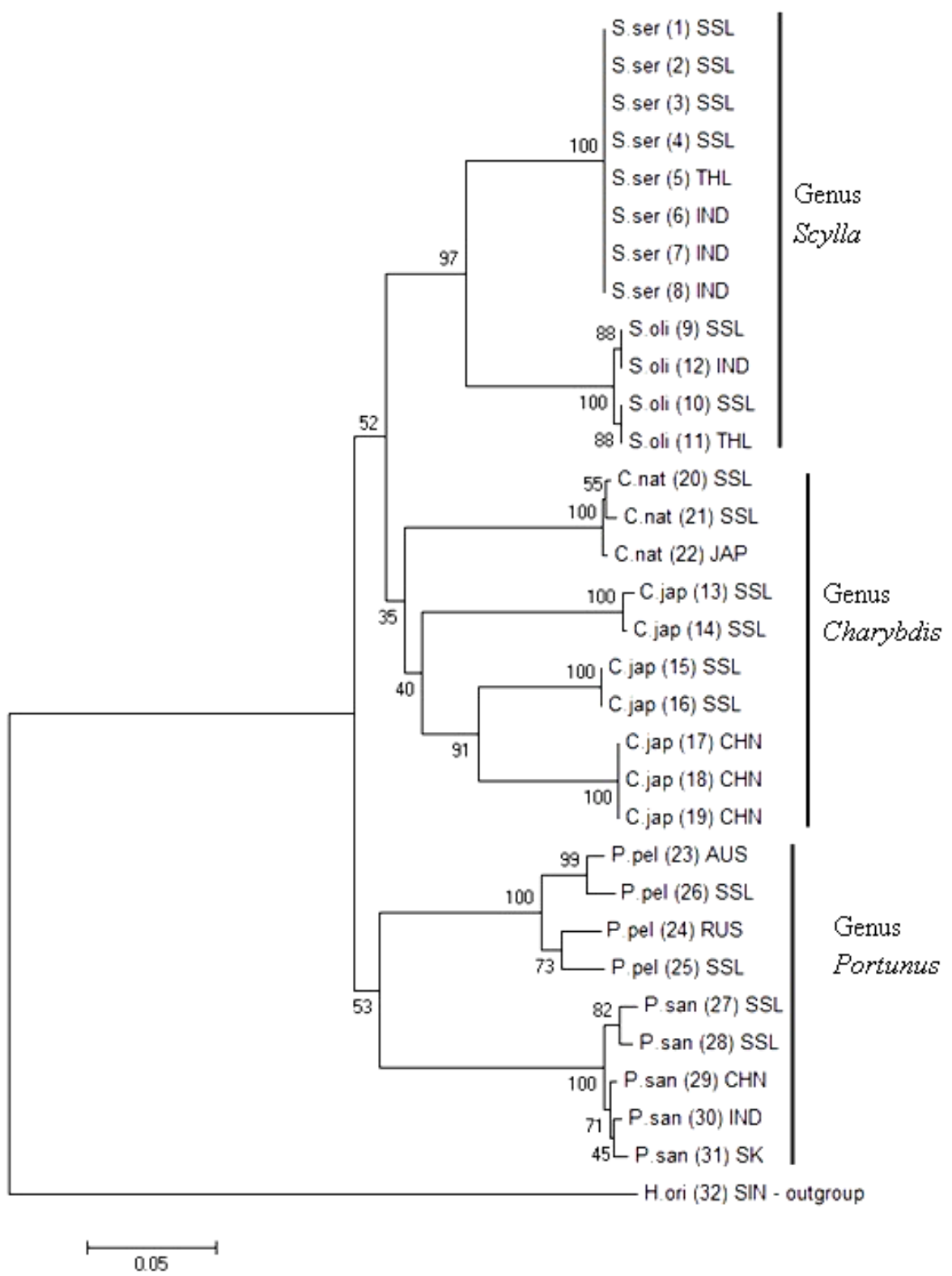

SSL - Southern Sri Lanka, JAP - Japan, SIN - Singapore, THL - Thailand, AUS - Australia, RUS - Russia IND - India, CHN - China, SK - South Korea

Figure 2. Minimum Evolution Tree derived for partial COI mitochondrial gene region of selected crabs from southern Sri Lanka and other geographical regions. 


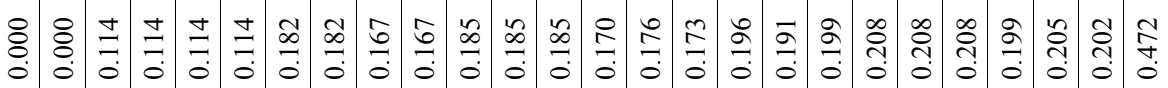

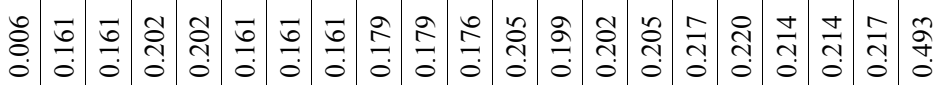

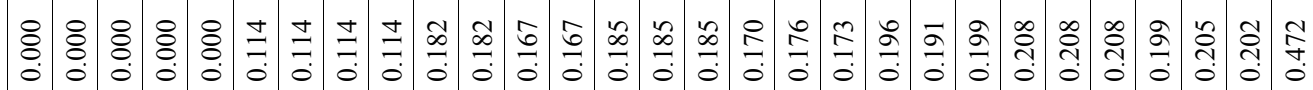

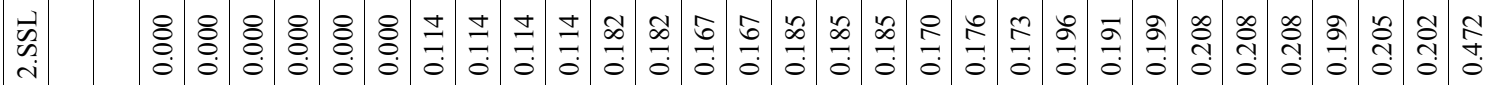

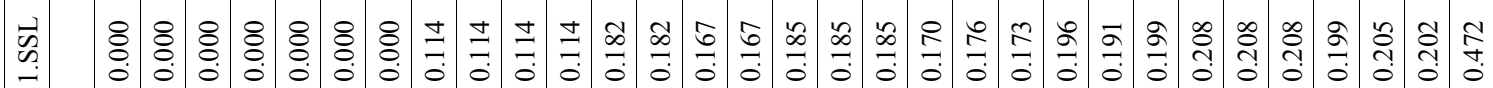

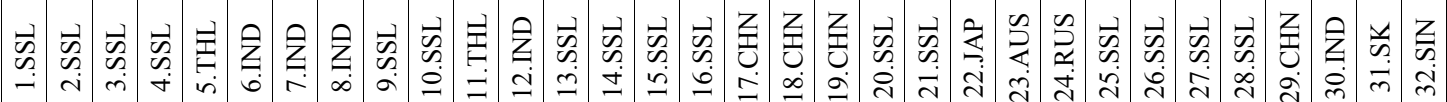

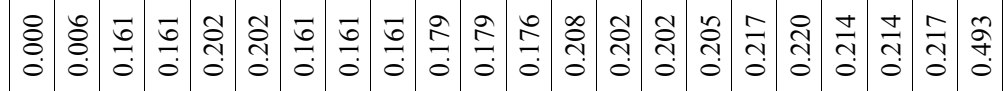

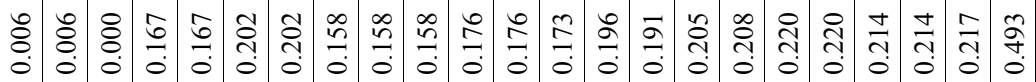

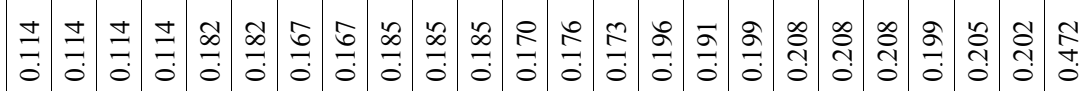

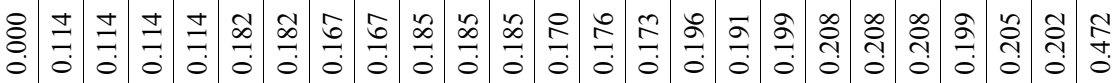

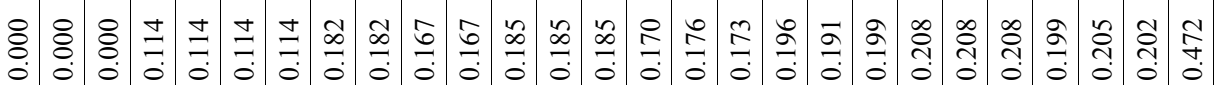

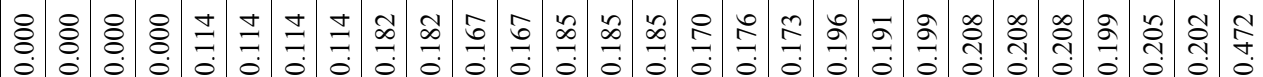

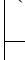




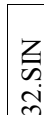

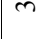

$\frac{v}{\infty}$

交

空

옹 옹

Zũ

옿옿옹

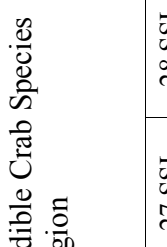

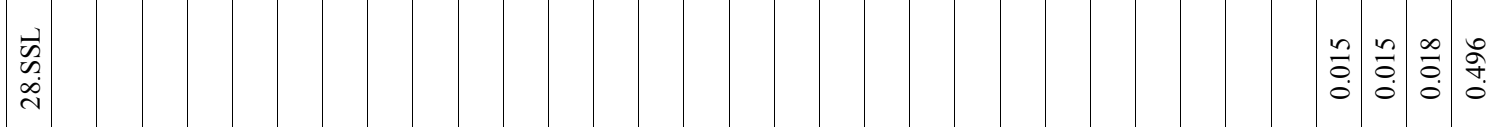

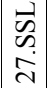

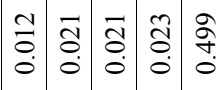

$\vec{w}$

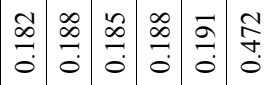

$\vec{W}$

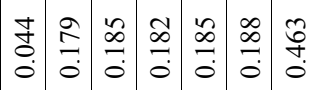

ते

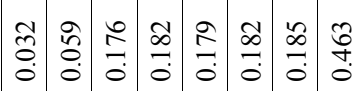

ㄱ.

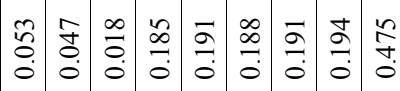

?ִ

ते

然

$\underset{\substack{a \\ \text { in }}}{ }$

क्ष

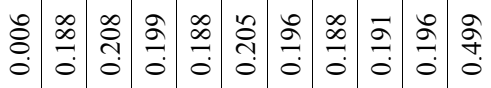

ปิ่

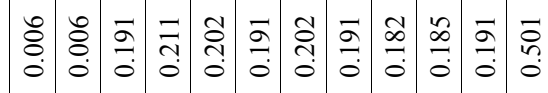

壼

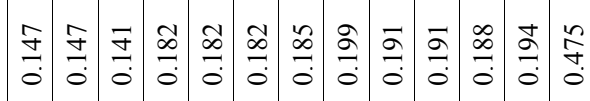

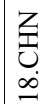

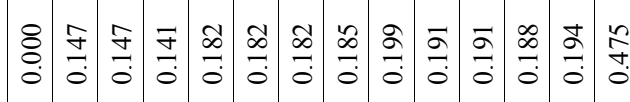

Ż.

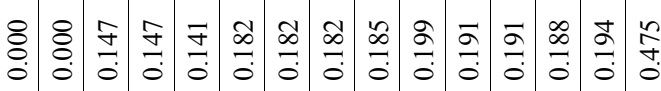

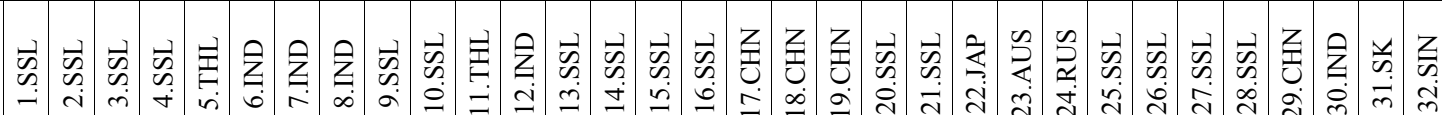




\section{Discussion}

\subsection{Determination of Species Status of Several Crab Morphs}

Among derived sequences, except two, others have been identified according to the blast results and revealing selected specimens belong to seven different species categorized under three genera. The species status of sequences results for Scylla tranquebarica have not been confirmed hence, have not been utilized for phylogenetic analysis. This was because only one sequence existed, which is not sufficient to generate conclusions. On the other hand, its identification in BLAST was also vague.

\subsection{Determination of Phylogenetic Status of Identified Species}

According to the Minimum Evolution Tree (Figure 2) obtained, three different clades have clearly deviated according to genera, Genus Scylla, Genus Portunus, and Genus Charybdis. Separation of different clades revealed that Genera Scylla and Charybdis together exhibit more distant relation from Genus Portunus. Estimated sequence divergence levels among taxa used in this study are given in the Table 3.

With the aid of the level of divergence, it can be shown that Scylla serrata recorded from India, Thailand and southern Sri Lanka are of a greater genetic similarity which is further supported by a $100 \%$ bootstrap value. Yet, $S$. olivacea behaves in a different manner in which two sequences illustrate similarities with two different downloaded sequences. i.e. One specimen 10.SSL (refer to Table 2 for sequence identities) is compatible with the sequence reported from Thailand with a zero divergence. While additionally, specimen 9.SSL, is in connection with the Indian sequence with the same zero divergence. The bootstrap node support of these two varieties of S. olivacea is $100 \%$ (refer to Figure 1) and connections of each pair of compatible sequences are $88 \%$ of node support. This separation is a bit doubtful and further analysis is necessary. However, this might be resulted due to introduction of different varieties into Sri Lankan waters from anthropogenic or natural causes. Percentage divergence between these two Scylla species $(11.4 \%)$ is greater than $0.02(2 \%)$ - the interspecific genetic distance, according to Hebert et al. [8]. Therefore, their species identity is well pronounced. It can also be stated that southern Sri Lankan $S$. olivacea is related both to Indian and Thai species.

The clade named genus Charybdis, is comprised of two species, $C$. japonica and $C$. natator with a magnitude of divergence above $15 \%$. Two C. natator sequences behaved in a compatible manner with a very low divergence level of 0.006 . Those two sequences are in close relation in same 0.006 divergences with the Japanese variety. This reveals that there might be a good flow of genes in between Japan and Sri Lanka in the case of $C$. natator.
However, $C$. japonica exhibited a complex status. There are two varieties identifiable in colour pattern, but resulted in the same species according to the blast results. The phylogenetic tree shows that those two morphs have been separated clearly, i.e. 13.SSL and 14.SSL from 15.SSL and 16.SSL. Moreover, those two varieties are separated from reported Chinese sequences, 15 and 16 with $10 \%$ divergence and 13 and 14 with $15 \%$. Apart from that the two identified Sri Lankan morphs produce a divergence of $15.8 \%$. Therefore, their species level determination as the same species becomes controversial. Perhaps those varieties may belong to different species of the same genus or sub-species of same species as the morphology of two morphs also seems to be dissimilar. According to the results it can also be suggested the availability of cryptic species in the genus.

The last distinct clade, which consisted of Genus Portunus, has been conclusively subdivided in to the two species $P$. pelagicus and $P$. sanguinolentus. On the other hand, Genus Portunus can be considered as the basal clad which produces two sister-clads of genera Charybdis and Scylla. Two specimens of $P$. pelagicus are in relation with the sequences of two different geographical regions, Australia and Russia from which the divergence level of those two Sri Lankan sequences was recorded as $4 \%$.

Two sequences of $P$. sanguinolentus from southern Sri Lanka show a divergence level of $1.2 \%$. Therefore, it can be confirmed that those are two haplotypes of the above species. Apart from that $P$. sanguinolentus sequences show a relation with South Korea, India and China with fairly low divergence level of approximately $2 \%$. Thus, it can be confirmed that $P$. pelagicus and $P$. sanguinolentus are distributed in Indo-Pacific region with more or less similarities with sequences from those countries.

The classification for Scylla has been controversial since long. Ultimately, Keenan et al. [11] extensively revised the taxonomy of genus Scylla using both morphometric and genetic approaches, and divided this genus into four distinct species: S. serrata, S. olivacea, S. tranquebarica and Scylla paramamosain. Srinivasagm et al. [13] and Kathirvel et al. $[10]$ reported the presence of only two species i.e. $S$. serrata and S.tranquebarica in Indian waters. Presence of S. serrata along the south coast has been reported [12], but this study was able to identify the presence of three species of genus Scylla including S. olivacea in Southern Sri Lanka.

As observed, morphological variations are distinguishable among three of those species. S. serrata is more or less greyish-green in body colour where $S$. olivacea contains reddish-brown together with the dark green. The specimen identified as $S$. tranquebarica is more or less dark brown. Abdomen is clearly striped with brown coloured bands. It is important to consider the presence of the $S$. tranquebarica in association with $S$. olivacea as recorded by Keenan et al. [11]. Confirmation of the specimen, which resulted as $S$. tranquebarica is bit difficult, because only one specimen was encountered. Therefore, further collection of samples and analysis of data are essential in order to draw better conclusions. 
It is important to investigate the diversity of faunal groups and produce information in a standard way to internationally accepted data-bases, which can be utilized by other research. The current study published 12 sequences in databases NCBI and BOLD, among them KM0528130/SLCRB004-14, KM528131/SLCRB003-14, KM528124/ SLCRB001-14 and KM528125/SLCRB002-14 are unique and have not been recorded previously in Sri Lanka. According to the current study, the most abundant mud crab species in southern Sri Lanka is the $S$. serrata, when compared to other two species. Hence, it fetches the highest economic consideration due to the better taste as well. Further, as it was not documented, it is evidence of the availability of $S$. olivacea and $S$. tranquebarica in southern coastal region of Sri Lanka. Mud crab fisheries have been functioning in a considerable status in the country for several decades. With the high demand in and export of crab, this sector generates international economic activity, as well as and constitutes an important means of income generation for local riparian communities. However, the increase in coastal populations, the high demand for mud crabs from foreign countries, the ease of collection of in shallow coastal waters by traps, gill nets, scoop nets, hand picking and the introduction of fattening for soft shell ones, have all combined to cause overfishing of this valuable resource. In spite of the importance of mud crabs, information of their biology and ecology which is crucial for management is still in an undervalued condition in Sri Lanka.

Gained information, together with species status and their phylogenetic cognitions, may have a greater application in the development of the fisheries sector. There is also a greater utility in conservation and management practices of crab populations.

\section{Conclusions}

In the final analysis, it is evident that six different species of commonly available edible crabs are found along the southern coastal belt of Sri Lanka. However, three genera were suggested to inhabit in the study area with the species identity of Scylla serrata, Scylla olivacea, Portunus pelagicus, Portunus sanguinolentus, Charybdis japonica and Charybdis natator.

Concerning the divergence level, it can be concluded that Scylla serrata recorded from India and Thailand are in a greater genetic uniformity with the southern Sri Lankan specimens. However, Scylla olivacea behaved differently, one specimen was in genetic cognition with Thailand, and the other one with India.

In the case of Charybdis natator, it can be concluded that recorded specimen are in a strong relation with Japanese sequence. However, the phylogenetic status of suggested $C$. japonica samples is controversial and need further analysis for a better conclusion.
Genus Portunus is the basal clade which has produced other sister clads. By conferring with the relationships, the Indo-West Pacific distribution of Genus Portunus can be accepted.

\section{Acknowledgements}

Our praiseful gratitude is expressed to Professor N.V. Chandrasekharan; Palitha Harasgama; Technical Officer of Molecular Biology and Biotechnology Unit, Department of Chemistry University of Colombo, Sri Lanka for their support extended in collecting molecular data.

\section{REFERENCES}

[1] K. E. Carpenter, V. H. Niem. FAO Species identification guide for fishery purposes; the living marine resources of the western central pacific. Food and Agriculture Organization of the United Nations, Rome. 1998. Volume 2. 1115-1130

[2] F. O. Costa, J. R. de Waard, S. Ratnasingham, R. T. Dooh, M. Hajibabaei, P. D. N. Hebert. Biological identification through DNA barcodes: the case of the crustacea. Canada Journal of Fisheries and Aquatic Sciences. 64: 272-295, 2007.

[3] N. Dawnay, R. Ogden, R. McEwing, G. R. Carvalho. Validation of the barcoding gene COI for use in forensic genetic species identification. Forensic Science International. 173: 1-6, 2007

[4] R. Fuseya, S. Watanabe, Genetic variability in the mud crab genus Scylla (Brachyura: Portunidae). Fisheries Science. 62: 705-709, 1996.

[5] H. Fushimi, S. Watanabe. Problems in species identification of the mud crab Genus Scylla (Brachyura: Portunidae).US-Japan Natural Resources Technical Report. 28: 09-13, 2008.

[6] D. Gopurenko, J. M. Hughes. Regional patterns of genetic structure among Australian populations of the mud crab, Scylla serrata (Crustacea: Decapoda): evidence from mitochondrial DNA. Marine and Freshwater Research. 53: 849-857, 2002.

[7] P. D. N. Hebert, A. Cywinska, S. L. Ball, J. R. deWaard. Biological identifications through DNA barcodes. Proceedings of the Royal Society of London. 270: 313-321, 2003.

[8] P. D. N. Hebert, S. Ratnasignham, J. R. deWaard. Barcoding animal life: Cytochrome oxidase subunit I divergences among closely related species. Proceedings of the Royal Society of London. 270: 96-99, 2003.

[9] S. C. Jayamanne. Crab resource of Sri Lanka. 'Vidu', the magazine published by National Aquatic Resource Agency, Sri Lanka, 2011.

[10] M. Kathirvel, S. Kulasekhar, C. P. Balasubramanium. Mud crab culture in India. Central Institute of Brackish water Aquaculture (ICAR). 17: 60, 2004. 
[11] C. P. Keenan, P. J. F. Davie, D. L. Mann. A revision of the genus Scylla de Haan, 1833 (Crustacea: Decapoda: Brachyura: Portunidae). The Raffles Bulletin of Zoology. 46(1): 217-245, 1998.

[12] P. Maitipe, S. S. De Silva. The structure and function of krall, a fishing gear, in a Sri Lanka lagoon. Journal of Fish Biology. 33(1): 137-143, 1896.
[13] S. Srinivasagm, M. Kathirvel, S. K. Pandian. Captive, brood stock development induced breeding and larval stages of mud crabs (Scylla sp.). Central Institute of Brackish water Aquaculture (ICAR), India. 12: 26, 2000.

[14] K. M. Wilson. Molecular biology as a tool for taxonomy. Clinical Infectious Diseases. 20:192-208, 1995. 